\title{
Condition-dependent differences in male vibratory pre-copulatory and copulatory courtship in a nuptial gift-giving spider
}

\author{
Monika J. B. Eberhard ${ }^{1}$ (D) A Alexandra Machnis ${ }^{1} \cdot$ Gabriele Uhl $^{1}$ (D) \\ Received: 16 April 2020 / Revised: 21 September 2020 / Accepted: 12 October 2020 / Published online: 29 October 2020 \\ (C) The Author(s) 2020
}

\begin{abstract}
Condition-dependent secondary sexual traits and signals are often crucial for mate choice decisions. Nuptial gifts, provided by the male to the female during mating, may represent an indicator of male condition, especially if production of the gift is energetically costly. Additionally, other signalling modalities may well play a role in mate choice in such systems. Females of the nursery web spider Pisaura mirabilis preferably mate with males that provide a prey item wrapped in silk. Apart from the nuptial gift, vibrational signals employed during courtship and mating may reveal additional information about male condition. We tested condition-dependence of male vibrational signals of well-fed versus starved males, when in contact with female dragline silk and during mating trials. Our results show that vibrational signals are produced in P. mirabilis, both during pre-copulatory courtship and during copulation. Male courtship signals were condition-dependent: males in good condition initiated signalling earlier and emitted more vibrational pulses than poor-condition males. They were also more likely to be accepted by the female for copulation. We additionally identified vibrational signals during copulation. These signals were different from pre-copulatory courtship vibrations but did not differ between the treatment groups. This study shows that vibrational communication plays an important role before and during copulation in P. mirabilis. It sets the stage for further experiments on spider biotremology associated with nuptial gift giving behaviour.
\end{abstract}

\section{Significance statement}

Male courtship behaviour can indicate a male's condition and quality and be subject to female mate choice. Vibrational communication during mating plays a crucial role in many animal species. Spiders are known to be extremely sensitive towards vibrations, and there is evidence that vibratory signals are also used during courtship. Here, we study the nuptial gift-giving spider Pisaura mirabilis in which courtship entails providing a nuptial gift by the male to the female. The gift quality determines on the probability and duration of mating. We investigated the role of vibrational behaviour in this species by standardizing nuptial gifts. Our study demonstrates that vibratory signals comprise information about the male's condition, that signals are also produced during mating and that courtship and copulatory signals are strikingly different. We suggest that vibrational communication provides important condition-dependent traits for female mate choice in addition to the nuptial gift.

Keywords Courtship display $\cdot$ Copulatory courtship $\cdot$ Biotremology $\cdot$ Substrate vibration $\cdot$ Arachnida

Communicated by D. J Hosken

Supplementary Information The online version contains supplementary material available at https://doi.org/10.1007/s00265-02002918-w.

Monika J. B. Eberhard

monika.eberhard@uni-greifswald.de

1 Zoological Institute and Museum, General Zoology and Zoological Systematics, University of Greifswald, Loitzer Str. 26, 17489 Greifswald, Germany

\section{Introduction}

Secondary sexual traits, such as the antlers of deer or the dazzling colouration of many birds as well as their displays and songs, are considered costly and therefore usually condition-dependent (Zahavi 1975). Since such conditiondependent traits or signals are often indicators of the individual's underlying quality, they are crucial for mate choice decisions (Andersson and Simmons 2006). Nuptial gifts of prey items or male-produced secretions, which are presented to females during courtship, represent a special type of such male 
signal (Brown 1997; Vahed 2007). Provision of nourishment by the male to the female before, during or after mating, is known from many arthropods (Vahed 1998; Albo et al. 2013b; Prokop and Semelbauer 2017). If production of such a gift is energetically costly, its quality may represent an indicator of male condition, e.g. in terms of foraging efficiency (Kotiaho 2001; Bradbury and Vehrencamp 2011; Prokop and Semelbauer 2017).

In the nursery web spider Pisaura mirabilis (CLERCK, 1757), a cursorial hunting spider, males capture prey, wrap it in silk and offer this nuptial gift to the female during courtship (Austad and Thornhill 1986; Nitzsche 1999). Females prefer males that offer a nuptial gift, which results in increased copulation probability and copulation duration for males that offer a nuptial gift (Stålhandske 2001; Prokop 2006; Bilde et al. 2007), and increased amounts of sperm transferred to the female sperm storage organs (Albo et al. 2013a). Gift construction - especially the amount of silk used for preywrapping - is condition-dependent, as males in poor physical condition (starved) spend less time and less silk in prey wrapping than good-condition (satiated) males (Albo et al. 2011). Other costs for the males involved in providing a nuptial gift include hunting costs, a missed meal and carrying costs (Albo et al. 2011; Prokop and Maxwell 2012). In an experiment carried out by Albo et al. (2012), the nuptial gifts produced by satiated males were exchanged with the gifts produced by starved males. However, irrespective of the wrapping quality of the gifts, males in good condition were more successful in obtaining matings and had longer copulation durations than males in poor condition. Thus, the quality of the gift wrapping did not affect female mate choice despite being an indicator of male condition. Either females simply do not use the information provided by nuptial gift wrapping, or some other information/communication channel overrules the cues represented by the nuptial gift. Male body condition could be assessed by the females using chemical signals, such as cuticular pheromones. However, to date, there is no information on cuticular hydrocarbons in this spider species. Male condition could be visually assessed by the females, but, as most other spiders, $P$. mirabilis seems to have very poor shape recognition abilities (Uhl and Elias 2011; Land and Nilsson 2012). We hypothesized that females acquire information about the feeding status of males using vibrational signals males potentially produce during courtship.

Substrate vibrations are vastly used by animals for communication in various contexts (Cocroft and Rodríguez 2005; Hill and Wessel 2016). This communication channel is quite different from airborne acoustic signals, because even small animals such as insects or spiders are able to produce very low-frequency signals transmitted via the substrate (Greenfield 2002; Virant-Doberlet and Cokl 2004). Spiders, which rely heavily on substrate vibrations for prey capture, are especially sensitive to vibrations (Barth 2002) and also use vibrational signals in contexts such as mate localization, species recognition, mate selection, and aggressive interactions (Uhl and Elias 2011). Despite the important role of substrate vibration in spider communication, knowledge on the information transferred through vibrational signals in spiders is still limited. In some web-building spiders, male courtship vibrations are known to curtail female aggressiveness (Suter and Renkes 1984; Wignall and Herberstein 2013b; Wignall and Herberstein 2013a) or to stimulate receptive females into mating (Maklakov et al. 2003). In cursorially hunting spiders, which do not build a web to catch prey, substrate vibrations seem to be particularly important for species recognition (Barth and Schmitt 1991) and mate quality assessment (Rivero et al. 2000; Gibson and Uetz 2008; Elias et al. 2010). Because vibrational signals may be costly to produce and correlated with body size, immune competence or condition, they are considered to be reliable indicators of male condition and quality and are strongly associated to female mate preference (Kotiaho et al. 1996; Rivero et al. 2000; Ahtiainen et al. 2004; Wignall et al. 2014). All of these studies focussed on pre-copulatory mating behaviour, with relatively little attention to the signalling that takes place during copulation. However, signals during mating, known as copulatory courtship, could be used in the context of cryptic female choice and be therefore an important determinant of variation in male reproductive success (Eberhard 1994; Rodríguez 2019). In general, vibrational communication has rarely been investigated in the context of copulatory courtship and cryptic female choice. In a review by Rodríguez (2019) on vibrational signals during copulation, only 23 studies on arthropod taxaincluding three spider species - are listed.

To investigate our hypothesis that vibrational signals are employed before and during copulation and are dependent on feeding condition, we first identified the sequence of courtship behaviours of $P$. mirabilis and the various vibrational signals involved during a mating episode. We then tested condition-dependence of male vibrational signals by experimentally manipulating male body condition: we applied feeding regimes (satiated and starved males) that are known to affect male body mass and consequently body condition (Albo et al. 2012). Throughout the following sections, we always refer to "condition" as "phenotypic" condition (i.e. feeding condition). We investigated vibratory performance of well-fed versus starved males, when in contact with female dragline silk and during mating trials. In mating trials, we tested female mate choice and reproductive success, assessed as number of viable offspring in an egg sac. As we consider vibrational signalling costly, we predicted that males in good condition would produce more and more reliable (repeatable) vibratory courtship signals than males in poor condition. Females should use the information provided by males during courtship and mating, preferring good condition 
males (namely better signallers) as mates and experiencing a reproductive advantage by mating with these males.

\section{Material and methods}

We collected 180 sub-adult and juvenile $P$. mirabilis in April 2018 at three localities $(<3 \mathrm{~km}$ apart from each other) in Greifswald, Germany (54 $05^{\prime} 38.1^{\prime \prime} \mathrm{N} 13^{\circ} 22^{\prime} 17.9^{\prime \prime}$ E). Males and females were kept individually in round vials ( $9 \mathrm{~cm}$ height, $5 \mathrm{~cm}$ diameter), which were closed by foam lids. The vials were placed upside down in trays filled with water to maintain high humidity inside. Spiders were raised at room temperature $\left(23.7 \pm 0.6{ }^{\circ} \mathrm{C}, 47.0 \pm 9.4 \%\right.$ relative humidity $)$ under artificial light (three UV lamps, Exo Terra Repti Glo 10.0, 10\% UV-B, 33\% UV-A, 20 Watts) set to a natural photoperiod (light: 8:00-18:30). Every third day, each spider was fed with a common green bottle fly (Lucilia sericata) until the final moult to adulthood. Subsequently, males were divided randomly into two feeding regimes: good-condition males ( $n$ $=29$, satiated males) were fed as before, while poor-condition males were not fed any longer ( $n=29$, starved males). Females were fed as before the final moult. All experiments were carried out with adult males and females, 14-20 days after their final moult (and in the respective feeding regime). The feeding regimes were chosen in accordance to earlier studies on P. mirabilis feeding conditions (Albo et al. 2011; Albo et al. 2012), and there was no mortality observed in any of the groups in our treatments.

As the production of the nuptial gift is dependent on male condition (Albo et al. 2011), we avoided confounding effects between male condition and gift quality by using standardized nuptial gifts. To obtain these, another group of well-fed males was used. These males $(N=12)$ received equally sized flies and were allowed to wrap their caught prey for $1-3 \mathrm{~h}$. Nuptial gifts (mean weight $22.4 \pm 2.5 \mathrm{mg}$ ) were then carefully removed from these males with forceps and offered immediately to the experimental males at the beginning of each experiment. According to Bilde et al. (2007), switching of gifts between males does not affect their behaviour.

With each male, we conducted two experiments: in a first experiment, males were exposed to the dragline silk of a randomly selected female to record pre-copulatory vibrational signals without direct contact to the female. In a subsequent second experiment, male (and female) copulatory vibrations were measured during a mating trial with the female whose dragline silk had been used in the first experiment.

\section{Experiment 1: courtship vibration and male condition}

In the first experiment, we allowed an adult, virgin female (ca. 14 days after the final moult) to move freely in the arena for $10 \mathrm{~min}$ to leave her silk draglines on the arena floor.
Subsequently, we carefully removed the female and placed a male into the arena. When a male touches the silk of an adult female, it starts producing vibrational signals by tremulating its opisthosoma (Nitzsche 2011). After ca. 2 min, the male was offered a standardized nuptial gift (see above), and all vibrational signals of the male were recorded for $11 \mathrm{~min}$. To record all substrate vibrations during courtship, we used the corpus of a drum (TomTom, Magnum, $30 \mathrm{~cm}$ in diameter), covered with stretched nylon fabric as experimental arena. The sides of the arena were covered with a plastic frame and black cardboard to prevent spiders to escape and to prevent visual distractions. A small piece of reflective plastic tape (ca. $1 \mathrm{~mm}^{2}$ ) was fixed in the middle of the arena to serve as measurement point for the laser vibrometer (PDV-100, Polytec Gmbh, Waldbronn, Germany). Petroleum jelly was placed on the inside of the arena walls to prevent spiders from climbing up. The laser pointed perpendicularly onto the arena and was set to a velocity measurement range of $20 \mathrm{~mm} / \mathrm{s}$. Recordings were digitized (USB-connection-box VIB-E-220, Polytec, Waldbronn, Germany) and stored using the Software VibSoft 5.3 (Polytec GmbH, Waldbronn, Germany). Recordings were analysed either directly in VibSoft or on .wav-converted files using Audacity software (version 2.1.1, http://audacityteam. org). To minimize observer bias, blinded methods were used when the behavioural data were analysed.

To compare the vibratory performance of males varying in body condition, we counted the number of all pulses (opisthosoma tremulations) emitted during the experiment, and measured pulse intervals as well as dominant frequency of the vibratory pulses for the first 10-30 pulses emitted during the experiment and the last $10-30$ vibratory pulses (number dependent upon available pulses per recording) using fastFourier-transformation with Hanning weighting function (FFT size: 16,384). This allowed us to observe differences of vibratory performance immediately at initiation of courtship, as well as ca. 10 min of courtship. Vibratory pulse interval was measured as time elapsed from the start of one pulse until the start of the following pulse. For the courtship vibration signals, we additionally calculated the coefficient of variation $(\mathrm{CV}=(\mathrm{SD} /$ mean $) \times 100)$ as an index of between-male variability for each trait per treatment group. To reveal withinmale variability of pulse intervals (and therefore assess whether the pulses were repeated regularly or not), we calculated within-male CVs for pulse intervals at the beginning and end of the experiment, as well as for all intervals together. We also noted latency from the start of the experiment until the first vibrational signal.

\section{Experiment 2: mating, copulatory vibration and male condition}

Within $30 \mathrm{~s}$ after the first experiment had ended, we started the second experiment by reintroducing the female that had 
deposited silk for the courtship vibration experiment. All males except one still held their nuptial gift. We registered the following male behaviours: latency to courtship vibration (duration from introduction of the female until first courtship vibration), insertion latency (duration from start of the experiment to copulation, i.e. insertion of the male pedipalp into the female genital opening), mating duration (measured as insertion duration: summed time of pedipalp insertion until disengagement), number of insertion events and latency and duration of the "gift-handling position" (face-to-face position of male and female - see "Results"). We also recorded frequency and duration of death feigning (thanatosis) (Hansen et al. 2008; Ghislandi et al. 2017). The experiment was terminated when the couple separated or after a maximum of $2 \mathrm{~h}$. Three additional matings were recorded with a high-speed video camera (Phantom Miro LC320S) at 3600 frames per second and analysed using Phantom Camera Control software (Cine Viewer Application, Vision Research Inc., USA) to assess whether only the male produces vibrations, or if also the female is involved in vibrational communication at that stage of mating.

To compare copulatory vibratory performance of the treatment groups, we measured the number, lengths and dominant frequency of the vibrations during the first insertions that took place. Insertion durations differed between individuals; we therefore calculated the pulse rates (pulses per second) by dividing the number of vibratory pulses by the insertion duration analysed (IV1 and IV2 separately_-see "Results" and Fig. $2 \mathrm{~d}$ for definition). Additionally, we counted the number of IV1 pulses that had been emitted without direct connection to IV2. Subsequent to the mating experiment, individuals were weighed on a microscale (Sartorius ME5). Males were then chilled in a freezer and preserved in $70 \%$ ethanol. Tibiapatella lengths (in $\mathrm{mm}$ ) of first leg on the right side were measured as a proxy for total body size. Measurements were taken under a Zeiss Discovery V.20 MRc stereomicroscope with $\times 0.63$ objective, connected to a Zeiss AxioCam MRc, using the corresponding software AxioVision 4.8 (all Carl Zeiss AG, Oberkochen, Germany). Male condition index was calculated as residuals of a linear regression of $\ln -$ transformed leg lengths and weights of the individual spiders (Jakob et al. 1996). Mean condition index was $0.09 \pm 0.12$ (median 0.09, 0.06 SIQR) for good-condition males and $-0.09 \pm 0.12$ (median $-0.11,0.08$ SIQR) for poorcondition males (Mann-Whitney $U$ test, $U=744, p<$ 0.001 ). Condition indices of females did not differ between groups (Mann-Whitney $U$ test, $U=490, p=0.11$ ).

We continued to keep females individually under the same conditions as prior to the experiments and provided them with prey (flies) every third day. In case of an oviposition event, the female and her egg sac were transferred into a larger box with finer netting to prevent hatched spiderlings from escaping. At the day of hatching of the spiderlings from the egg sac, we counted live and dead spiderlings as well as unfertilized eggs of the first egg sac produced by each female ( $=$ fecundity) and calculated fertilization success as the percentage of hatched spiderlings vs. all eggs produced (sum of all spiderlings + unfertilized eggs). Females were then chilled in a freezer, preserved in $70 \%$ ethanol and leg lengths measured as above.

We identified vibrational signals and the sequence of behaviours necessary for a successful copulation during both experiments, by noting all behavioural elements that took place for the males of the good condition group $(n=29)$.

\section{Statistical analyses}

To compare vibrational performance between groups (latencies, durations, pulse numbers, intervals and dominant frequencies), we used non-parametric statistical tests (MannWhitney $U$ tests), due to non-normal distribution of most parameters (Shapiro-Wilk normality tests, $p<0.05$ ). To assess whether male mating success depended on vibratory performance or other parameters, we performed generalized linear models (binomial distribution) using (i) insertion (y/n) and (ii) female fertility as response variable and the various parameters measured during our experiments as fixed effects. Calculation of fertility was implemented in $\mathrm{R}$ using the command cbind (number of hatched spiderlings, number of eggs number of hatched spiderlings) (see Pekár and Brabec 2016). Subsequently, full models were reduced by removing nonsignificant variables until a final model was received. To correct for overdispersion in the data, we used a quasi-binomial model for fertility. Model quality (normality of residuals, homoscedasticity) was visually assessed. Analyses were performed using SPSS (IBM SPSS Statistics, version 22), and R (https://www.r-project.org/) using RStudio (version 1.1. 383, RStudio Inc.). If not stated otherwise, data are presented as medians \pm SIQR. The dataset generated during this study can be found in Supplementary Table 1.

\section{Results}

First, we assessed all vibrational communication signals and behaviours associated with, and presumably necessary for, a successful copulation in P. mirabilis, based on the males of the good condition group (Fig. 1). Since detailed descriptions of the vibrational courtship in P. mirabilis are lacking so far (few details can be found in Nitzsche 1999, 2011), we provide them here (with percentage of males performing the given behaviour in parentheses).

After contacting female silk, male $P$. mirabilis usually produce vibrational signals by tremulating their opisthosoma and transferring resulting vibrations via their legs to the ground $(100 \%, n=29)$. These tremulations, called courtship signals herein, are short (ca. $0.2 \mathrm{~s})$ low-frequency pulses $(57 \pm 1.5 \mathrm{~Hz}$ 


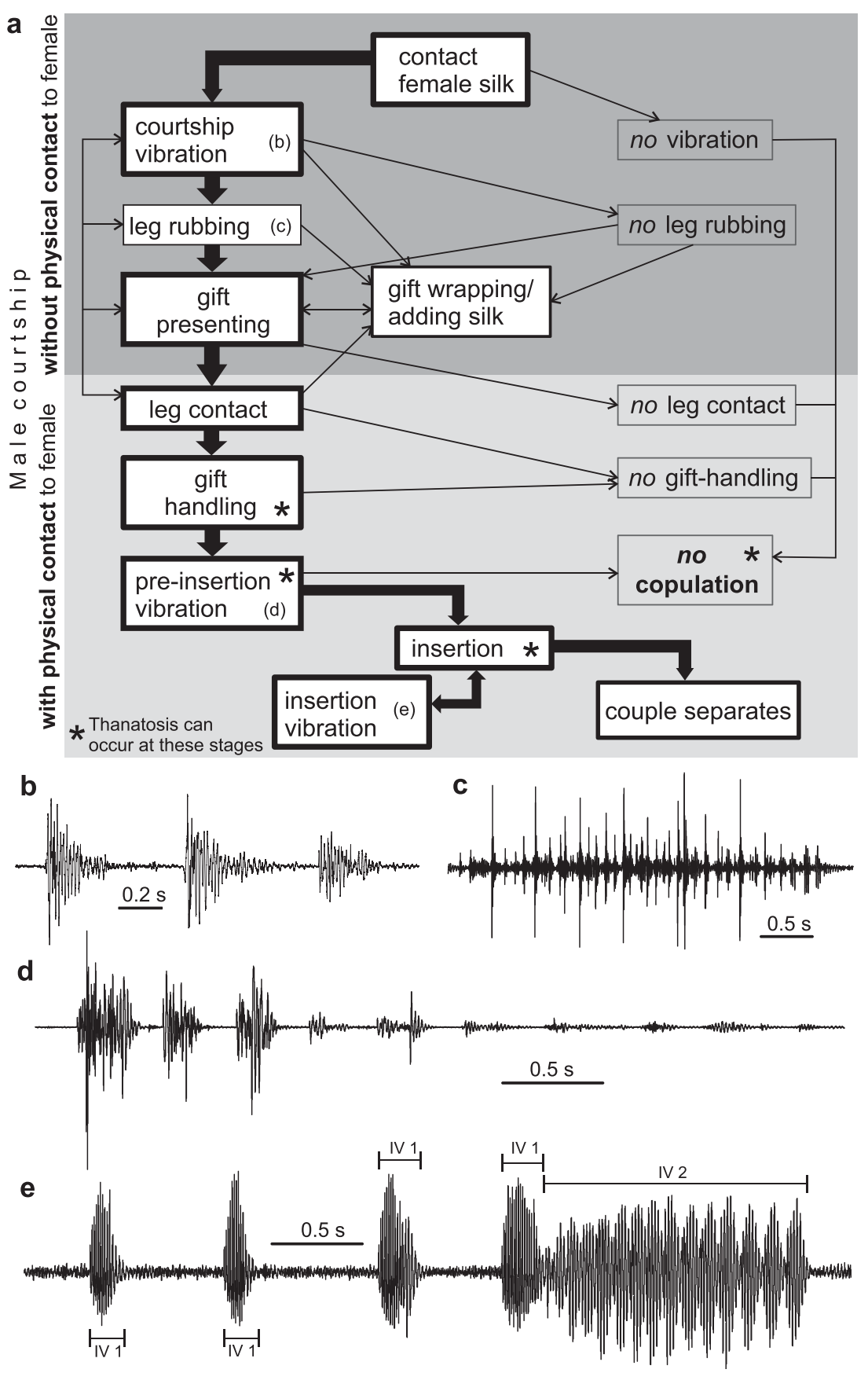

Fig. 1 Sequence of behavioural (a) and vibrational (b-e) components involved in courtship and mating of Pisaura mirabilis. a Thick lines and arrows depict the sequence of behaviours usually observed, while thin arrows depict behavioural sequences that can also occur. Thicklined behavioural components are presumably necessary steps for a successful mating. The darker grey area shows male behaviour after he had contact with the dragline of a female, but without physical contact to the female. The lighter grey area shows behaviours associated to males in physical contact with a female. Thanatosis can occur at the stages marked with a star. b-e Vibrograms of male substrate vibrational signals produced during courtship and copulation of P. mirabilis. b Courtship

dominant frequency, $n=29$ ) and repeated at regular intervals (702 $\pm 59 \mathrm{~ms}, n=29)$. The signal starts with high amplitude and gradually attenuates (Fig. 1b). Additionally, males vibration consists of regularly repeated low-frequency pulses, produced by male opisthosoma tremulation. c Leg-rubbing occurs when the male rubs his legs of one side of his body towards each other, usually 1st and 2nd or 1 st-3rd legs. d Pre-insertion vibration occurs during the gifthandling position, when the male pushes the female backwards and then moves underneath her for copulation. e Insertion vibration was observed during insertion of the male pedipalp into the female genital opening. While insertion vibration part 1 (IV1) is produced by the male while inflating and deflating the hematodocha of his pedipalp, insertion vibration part 2 (IV2) may be produced by the female. Amplitudes of a-d are not at equal (arbitrary) scales

occasionally rub their legs (usually 1 st and 2 nd or 1 st-3rd legs of one side) against each other, which elicits irregular but characteristic substrate vibrations (Fig. 1c). Wrapping of the 
nuptial gift with more silk can also be observed at this stage of courtship (Fig. 1a). As soon as the male contacts the female with his legs, he presents the nuptial gift in his chelicerae to her with the first pair of legs raised up, leaning backwards and facing the female $(89.7 \%, n=29)$. The female usually contacts the gift with her chelicerae and starts feeding on it. This "gifthandling" position is obligatory for subsequent copulation events (Fig. 1a). The male then pushes the female backwards and produces $2-5$ short vibratory pulses of high amplitude, followed by several pulses of lower amplitude (Fig. 1d; $86.2 \%, n=29)$. These "pre-insertion vibrations" are typical elements leading to a successful copulation (Fig. 1a). Then, the male moves underneath the female and inserts either the right or the left pedipalp into the female genital opening (insertion duration of one pedipalp was $15 \pm 13 \mathrm{~min}$ for the wellfed males in our experiments; $79.3 \%, n=29$ ). During insertion (when the hematodochae - the structure which creates the pressure to inject sperm into the female genitalia-is expanded and subsequently deflated), we recorded a so-called insertion vibration of a characteristic structure, which consists of two distinct parts (Fig. 1e; $100 \%, n=23$ ): insertion vibration part 1 (IV1) are short pulses of stable amplitude and higher dominant frequency $(229 \pm 30 \mathrm{~ms}, 90 \pm 5.9 \mathrm{~Hz}$; more broad band with 2-3 major frequency peaks); usually, 3-4 pulses are repeated in a sequence. These IV1 pulses are usually followed by insertion vibration part 2 (IV2) which is characterized by a longer series of repeated low-frequency pulses (duration $722 \pm$ $163 \mathrm{~ms}$, dominant frequency: $58 \pm 2 \mathrm{~Hz}$, quite narrow-band: Fig. 1e). This second part of the insertion vibration can be lacking; inspection of high-speed video recordings did not unambiguously reveal which sex produced IV2. During courtship and mating, thanatosis can occur when the female starts moving around $(82.8 \%, n=29)$ : The male holds on to the nuptial gift with his chelicerae, stretches its legs and is dragged along in this position by the female. Thanatosis can be observed during several stages of courtship (marked with a star in Fig. 1a). After several insertion events $(3 \pm 0.75)$, the couple separates usually without showing aggressive behaviour. The nuptial gift remains with the female in most cases $(69 \%, n=29)$.

Due to the results obtained from our behavioural observations, we decided to focus on courtship vibrations and copulatory vibrations, because they were always associated with a successful copulation and easy to identify due to their characteristic structure (compared with the irregular vibrations elicited by leg rubbing and gift wrapping).

\section{Experiment 1: courtship vibration and male condition}

After contacting female silk, all males of the good-condition group initiated courtship vibrations (Table 1), while poorcondition males were less likely to perform courtship vibrations $\left(100 \%\right.$ versus $\left.72 \% ; \chi^{2}=9.28, \mathrm{df}=1, p<0.01\right)$. Those poor-condition males that courted, started with slightly but not significantly longer latency (Fig. 2a) and produced significantly less vibratory pulses than good-condition males during the experiment (Fig. 2b; Table 1). Males of both groups exhibited regular pulse intervals at beginning of tremulation (Fig. 2c): within-male variability for pulse intervals was slightly but not significantly lower for males in good condition than for males in poor condition (good-condition $\mathrm{CV}=$ 27.7\%, poor-condition $\mathrm{CV}=37.9 \%, U=219, p=0.093$ ). At the end of the experiment, ca. 10 min after putting the males into the test arena, intervals of courtship vibrations increased for both experimental groups (Wilcoxon-signed rank tests: good-condition males $\mathrm{W}=283.5 N=28, p=0.006$; badcondition males $\mathrm{W}=189, N=20, p=0.002$ ), and in comparison, intervals were significantly longer for poor-condition males (Table 1; Fig. 2d). Within-male variability for pulse intervals was lower for males in good condition than for males in poor condition (within-male CV pulse interval at end of experiment: good-condition $\mathrm{CV}=25.9 \%$, poor-condition $\mathrm{CV}=38.1 \%, U=149, p=0.006$ ). This was also true for an overall comparison of within-male variability of pulse intervals (good-condition $\mathrm{CV}=32.5 \%$, poor-condition $\mathrm{CV}=$ $41.2 \%, U=171, p=0.009$ ). Vibrational courtship signals had a dominant frequency of $57-58 \mathrm{~Hz}$ throughout the experiments for both groups, and neither differed between groups nor between the beginning and end of the experiments (Table 1).

Variability between males was highest in the latency to initiate courtship vibrations with $\mathrm{CVs}$ higher than $100 \%$ for both treatment groups (Table 1). The number of pulses emitted during the experiment varied less for good condition males than for poor-condition males, whereas variability of intervals exhibited CVs of 12 24\% (Table 1).

\section{Experiment 2: mating, copulatory vibration and condition}

When the female was put into the arena, most males of both groups resumed producing courtship vibrations. There was no difference between the two groups any more concerning production of courtship vibrations ( $90 \%$ vs. $72 \%, \chi^{2}=2.97, \mathrm{df}=$ $1, p=0.09$ ). Males of good condition were more likely to get in contact with the female and to engage in the gift-handling position than starved spiders ( $93 \%$ vs. $72 \%, \chi^{2}=4.35, \mathrm{df}=1$, $p<0.05$ ), and they were also more likely to initiate insertion successfully ( $79 \%$ vs. $34 \%, \chi^{2}=11.89, \mathrm{df}=1, p<0.01$ : Fig. 3a).

Among the males that were accepted by the female, goodcondition males $(n=23)$ had significantly shorter insertion latencies than poor-condition males $(n=10)$ (Table 2; Fig. $3 \mathrm{~b})$. Additionally, starved males resumed the gift-handling position longer than well-fed males (Table 2; Fig. 3d). None 
Table 1 Medians ( \pm SIQR), as well as between-male coefficients of variation (CV) of durations and numbers of vibrational courtship signals performed by males varying in their body condition (good-condition and poor-condition) when in contact with female silk (without female presence; experiment 1 )

\begin{tabular}{|c|c|c|c|c|c|}
\hline \multirow[t]{2}{*}{ Response variable } & \multicolumn{2}{|c|}{ Good-condition group } & \multicolumn{2}{|c|}{ Poor-condition group } & \multirow[t]{2}{*}{$p$ value, $U$ test } \\
\hline & Median \pm SIQR & $\mathrm{CV}(\%)$ & Median \pm SIQR & $\mathrm{CV}(\%)$ & \\
\hline Latency to courtship vibration (s) & $\begin{array}{l}20 \pm 12 \\
N=29\end{array}$ & 131.1 & $\begin{array}{l}38 \pm 54.5 \\
N=21\end{array}$ & 132.3 & $U=213.5, p=0.07$ \\
\hline Number of pulses & $\begin{array}{l}569 \pm 97.5 \\
N=29\end{array}$ & 34.8 & $\begin{array}{l}185 \pm 42.5 \\
N=21\end{array}$ & 76.5 & $U=537, p<0.001$ \\
\hline Pulse interval beginning (ms) & $\begin{array}{l}651.5 \pm 46.3 \\
N=29\end{array}$ & 14.3 & $\begin{array}{l}652.5 \pm 69.5 \\
N=21\end{array}$ & 19.9 & $U=290, p=0.78$ \\
\hline Dominant frequency beginning $(\mathrm{Hz})$ & $\begin{array}{l}57 \pm 1.5 \\
N=29\end{array}$ & 7.1 & $\begin{array}{l}58 \pm 2 \\
N=21\end{array}$ & 7.1 & $U=253, p=0.31$ \\
\hline Pulse interval end (ms) & $\begin{array}{l}701.8 \pm 59.8 \\
N=28\end{array}$ & 11.9 & $\begin{array}{l}787.8 \pm 82.3 \\
N=20\end{array}$ & 23.5 & $U=149, p<0.01$ \\
\hline Dominant frequency end $(\mathrm{Hz})$ & $\begin{array}{l}57.0 \pm 3.3 \\
N=28\end{array}$ & 7.4 & $\begin{array}{l}58.5 \pm 2.6 \\
N=20\end{array}$ & 8.5 & $U=257, p=0.63$ \\
\hline Interval beginning/end-ratio & $\begin{array}{l}0.90 \pm 0.08 \\
N=28\end{array}$ & 18.9 & $\begin{array}{l}0.83 \pm 0.09 \\
N=19\end{array}$ & 22.2 & $U=358, p=0.10$ \\
\hline
\end{tabular}

Significant $p$ values are highlighted in italics

of the other behavioural components during courtship and mating differed between treatment groups; starved males had more variable insertion durations (Table 2; Fig. 3c). The vibrational signals produced during insertion did not differ significantly in duration or dominant frequencies between males of the treatment groups. However, well-fed males produced more IV1 pulses without the direct connection to IV2 (Table 2).

Seven of ten females that had mated with a male of the poor-condition group produced an egg sac, while 20 of 23 females that mated with a good-condition male produced one (Fisher's exact test, $p=0.34$ ). Egg sacs of females contained similar numbers of eggs (good-condition males: $109.5 \pm 1$ vs. poor-condition males: $96 \pm 14.3$; MannWhitney $U$ test $U=71, p=1.00$ ), and fertility did not differ between treatment groups (good-condition males, $n=17: 19.7$ $\pm 36.0 \%$ vs. poor-condition males, $n=4: 81.3 \pm 45.5 \%$; Mann-Whitney $U$ test $U=77.5, p=0.89$ ).

The number of pulses emitted during the first experiment was significantly associated with mating success, and there was a significant interaction between male condition index, number of pulses and latency to start producing courtship vibrations (Table 3). For experiment 2, the latency to mate was the only variable that was significantly associated with fertility, with males accepted by the female to mate earlier having more viable offspring. We also found an interaction of condition index, insertion latency and mating durationwhile males in good condition had similarly long insertion durations, males in bad condition could achieve longer insertion durations when they were allowed to initiate copulation earlier, which resulted in more viable offspring for these males (Table 3). As only four of the matings with poor-condition males produced viable offspring, further statistical analyses between treatment groups were not possible in this respect.

\section{Discussion}

Our study demonstrated that vibrational signals are produced in P. mirabilis, both during pre-copulatory courtship and during copulation. Concerning pre-copulatory courtship, our results provide evidence that male vibrational signals are condition-dependent and may provide the female with information about male feeding condition. Males in better condition initiated signalling earlier and emitted more pulses within the given time frame (Table 1; Fig. 2). Our results also show that males in good condition were better able to produce their courtship vibrations at more stable intervals (expressed as lower within-male CVs) despite a prolonged courtship. Additionally, interval lengths varied quite a bit between males $(\mathrm{CV}=11-23.5 \%)$. Under natural conditions, males probably follow the dragline of a female and continuously produce tremulations for extended periods of time, similar to lycosid spiders (e.g. Gibson and Uetz 2008), but this has not been investigated in detail for P. mirabilis. Courtship, especially when linked to motor performance, is energetically costly (Hoefler et al. 2008; Byers et al. 2010), so prolonged production of repeated opisthosoma tremulations may not be possible for males in poorer condition. This could well serve as a signal used in sexual selection and be exploited by female mate choice. Vibratory pulse rate and repeatability (expressed by stable intervals) might act as a handicap signal for female choice, similar to the situation found in the wolf spider Hygrolycosa rubrofasciata. In this cursorial hunting spider, 

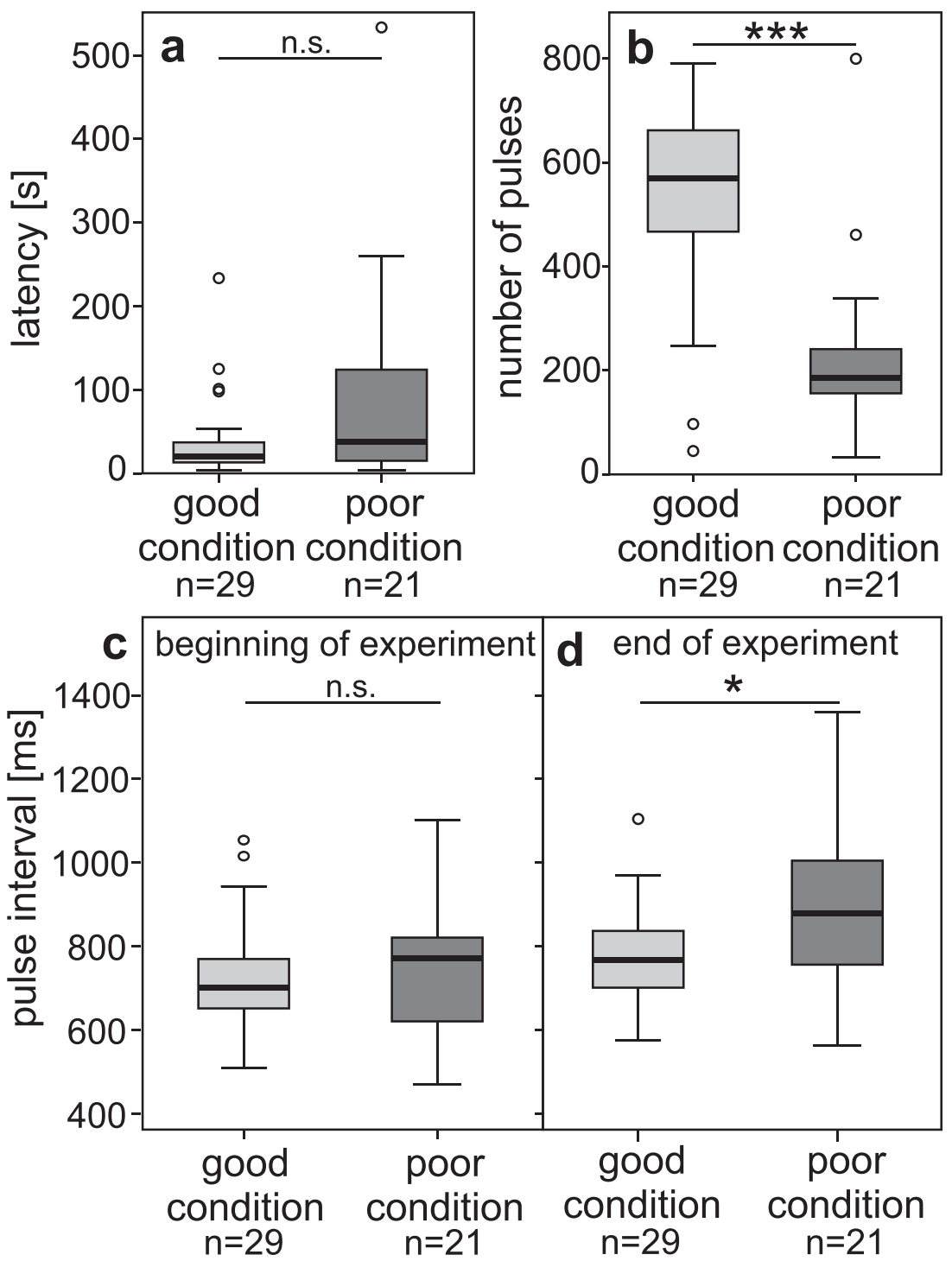

Fig. 2 Comparison of the good-condition and poor-condition male groups' performance during courtship after having contacted female silk (experiment 1). Boxplots show medians (thick lines) and 1st and 3rd quartiles (box), whiskers depict 1st and 3rd quartiles $\pm 1.5 \mathrm{IQR}$; outliers are marked with a circle. a Latency to courtship vibration (the time between the start of the experiment and initiation of courtship vibrations) was not significantly shorter for satiated than for starved males, but with higher variance for starved males. b Males in good condition emitted

which drums its opisthosoma onto the ground to produce vibrations, signalling rate and length is considered to serve as honest signals of male condition (Mappes et al. 1996; Rivero et al. 2000), and females prefer males producing higher drumming rates (Parri et al. 1997).

Production and presence of silk-wrapped prey as a nuptial gift offered from the male to the female is key for a successful mating in P. mirabilis (Stålhandske 2001) and might have evolved to reduce female aggression, expressed as precopulatory cannibalism, towards the male (Toft and Albo significantly more vibratory courtship pulses during the 11-min experiment than males in poor condition, while $\mathbf{c}$ pulse interval was similar for both groups at the beginning of the experiment. $\mathbf{d}$ The last 10-30 courtship pulses emitted by the males at the end of the experiment had longer intervals than at initiation of courtship, and starved males exhibited longer intervals than satiated males. All tests: Mann-Whitney $U$ tests; n.s. not significant; $* p<0.05 ; * * * p<0.001$

2016). Once a male has sustained the costs of gift construction, other signals might become more relevant for female mate choice. Males that produced more and continuous vibrational courtship signals were more likely to be accepted for copulation by the female in our study (Table 3 ). We suggest that these signals represent a courtship display providing information about male feeding condition towards the female. Of course, playback experiments are needed to test whether females use the various information coded within male vibrational courtship signals for mate choice. 
Fig. 3 Comparison of the goodcondition and poor-condition male groups' performance during mating experiments (experiment 2). a Males in good condition were more likely to be accepted by the female for copulation (= insertion of the male pedipalp into the female genital opening) than males in poor condition $\left(\chi^{2}=\right.$ $11.89, \mathrm{df}=1, p<0.01)$. b The latency to mate (time elapsed between introduction of the female into the experimental arena and copulation) was significantly shorter for males in good condition than for males in poor condition. $\mathbf{c}$ For those males that successfully copulated, insertion duration (sum of all insertions) did not differ between treatment groups. d Males in poor condition stayed in the face-to-face gifthandling position longer than males in good condition (MannWhitney $U$ tests; n.s. not significant; $* p<0.05$ )
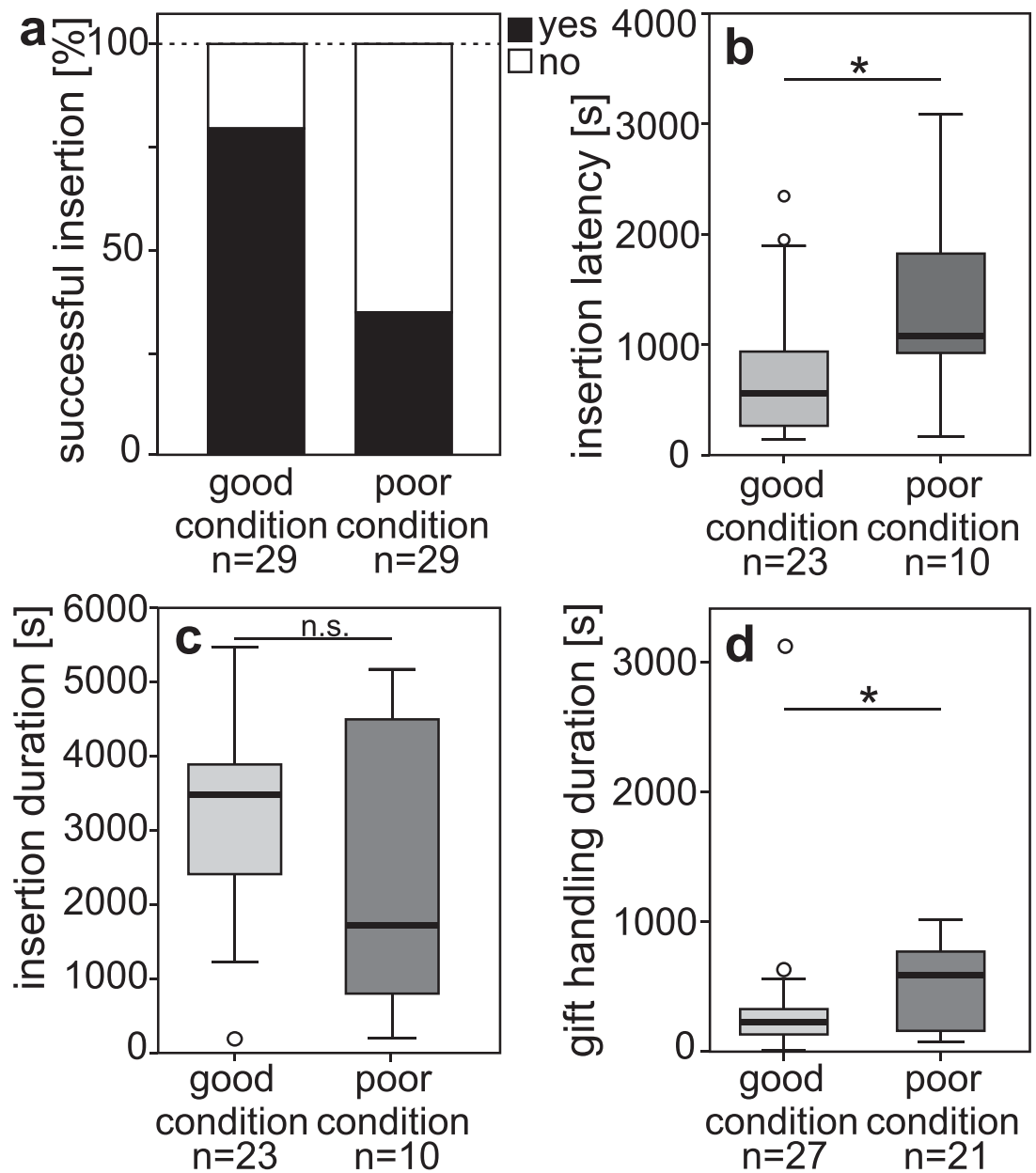

The dominant frequency of the courtship pulses did not differ between treatment groups, although it has been shown in wolf spiders that heavier males are able to produce lower maximum frequencies (Gibson and Uetz 2008). As nursery web spiders move around on various substrates such as leaf litter, soil and plants, signalling frequency might not be very informative, because different substrates will attenuate or amplify various frequency components differently (e.g. Mortimer 2017). In this study, we did not measure amplitude of the courtship signals because this trait would easily be confounded by proximity of a male to the female as well as by the substrate properties both are moving on. We therefore considered courtship vibration amplitudes and frequency an unlikely source of reliable information about male quality. This is corroborated by another study in a cursorial hunting spider, H. rubrofasciata, where signal frequency was not related to male size, and signal volume had low repeatability and was only weakly correlated with male size (Rivero et al. 2000).

Our study is the first to identify vibrational signals involved in copulatory courtship in P. mirabilis. During mating, copulatory signals produced by a male may serve to influence cryptic female choice in favour of the male (Eberhard 1994; Schäfer and Uhl 2002; Peretti et al. 2006), or to inhibit female aggressiveness (Becker et al. 2005). Signals produced by a female during copulation might function as a control mechanism for mate choice after copulation has been initiated, e.g. by stimulating certain male behaviours (Eberhard 1996; Rodríguez 1998; Peretti et al. 2006). Vibrational communication signals during copulation have rarely been investigated; Rodríguez (2019) found reports of 23 arthropod taxa. Among these, vibrational signals during copulation are usually similar to courtship signals produced before copulation. Only four species, namely one spider species Holocnemus pluchei (Huber 1995) and three pentatomid bugs, exhibited copulatory signals different from those produced before copulation. In P. mirabilis, the vibrational signals emitted during copulation were strikingly different from the courtship vibrations produced by males before copulation (compare Fig $1 \mathrm{~b}$ with 1e). Copulatory vibrations consist of two different components, called IV1 and IV2 herein (Fig. 1e). These parts differ in structure, length, repetition rate, amplitude and dominant frequency. High-speed video recordings revealed that IV1 is produced by the male during inflation and deflation of the 
Table 2 Median ( \pm SIQR) durations and numbers of vibrational signals and behavioural elements performed by males varying in their body condition (good-condition and poor-condition) during mating trials with a female (experiment 2)

\begin{tabular}{|c|c|c|c|}
\hline Parameter & Good-condition group & Poor-condition group & $p$ value, $U$ test \\
\hline \multicolumn{4}{|l|}{ Courtship and mating behaviour } \\
\hline \multirow[t]{2}{*}{ Latency to courtship vibration(s) } & $48 \pm 57.5$ & $80 \pm 287.5$ & $U=208, p=0.16$ \\
\hline & $\begin{array}{l}N=26 \\
290 \pm 360\end{array}$ & $\begin{array}{l}N=21 \\
480 \pm 392.5\end{array}$ & $U=254.5, p=0.55$ \\
\hline Latency to gift-handling (s) & $\begin{array}{l}N=27 \\
225 \pm 97.5\end{array}$ & $\begin{array}{l}N=21 \\
585 \pm 305\end{array}$ & $U=164.5, p<0.05$ \\
\hline \multirow[t]{2}{*}{ Insertion latency (s) } & $\begin{array}{l}N=27 \\
555 \pm 336.3\end{array}$ & $\begin{array}{l}N=21 \\
1082.5 \pm 372.5\end{array}$ & $U=57.5, p<0.05$ \\
\hline & $\begin{array}{l}N=23 \\
3481 \pm 439.3\end{array}$ & $\begin{array}{l}N=10 \\
1721 \pm 1507.8\end{array}$ & $U=152, p=0.16$ \\
\hline Insertion duration (s) & $\begin{array}{l}N=23 \\
3 \pm 0.75\end{array}$ & $\begin{array}{l}N=10 \\
2.5 \pm 1.4\end{array}$ & $U=118, p=0.92$ \\
\hline Insertion number & $\begin{array}{l}N=23 \\
400 \pm 215.6\end{array}$ & $\begin{array}{l}N=10 \\
360 \pm 281.4\end{array}$ & $U=107.6, p=0.77$ \\
\hline Thanatosis duration (s) & $N=24$ & $N=18$ & \\
\hline \multicolumn{4}{|l|}{ Copulatory vibration signals } \\
\hline \multirow[t]{2}{*}{ IV1 duration (ms) } & $228.8 \pm 29.5$ & $200.5 \pm 21.3$ & $U=123, p=0.43$ \\
\hline & $\begin{array}{l}N=23 \\
0.33 \pm 0.09\end{array}$ & $\begin{array}{l}N=9 \\
0.25 \pm 0.12\end{array}$ & $U=128, p=0.32$ \\
\hline \multirow[t]{2}{*}{ IV1 rate without IV2 $\left(\mathrm{s}^{-1}\right)$} & $\begin{array}{l}N=23 \\
0.14 \pm 0.07\end{array}$ & $\begin{array}{l}N=9 \\
0.07 \pm 0.05\end{array}$ & $U=151, p<0.05$ \\
\hline & $\begin{array}{l}N=23 \\
90 \pm 5.9\end{array}$ & $\begin{array}{l}N=9 \\
85 \pm 9.5\end{array}$ & $U=121.5, p=0.46$ \\
\hline IV1 dominant frequency $(\mathrm{Hz})$ & $\begin{array}{l}N=23 \\
722.0 \pm 163.4\end{array}$ & $\begin{array}{l}N=9 \\
840.8 \pm 291.3\end{array}$ & $U=61.5, p=0.17$ \\
\hline IV2 rate $\left(\mathrm{s}^{-1}\right)$ & $\begin{array}{l}N=23 \\
0.04 \pm 0.02\end{array}$ & $\begin{array}{l}N=8 \\
0.06 \pm 0.04\end{array}$ & $U=84, p=0.74$ \\
\hline \multirow[t]{2}{*}{ IV2 dominant frequency (Hz) } & $\begin{array}{l}N=23 \\
58 \pm 2\end{array}$ & $\begin{array}{l}N=8 \\
59 \pm 2.4\end{array}$ & $U=76.5, p=0.49$ \\
\hline & $N=23$ & $N=8$ & \\
\hline
\end{tabular}

Significant $p$ values are highlighted in italics hematodocha of his pedipalp. This vibrational signal was produced repeatedly during copulation, often without a direct connection to IV2. We were not able to associate IV2 with the male or the female. Due to the structure and chronological order, IV1 and IV2 might represent a copulatory courtship duet between male and female. Males in good condition produced more IV1 without following IV2 than males in poor condition. Apart from this, the measured characteristics of the vibrational signalling during copulation did not differ between the two treatment groups and was not associated with hatching success. It may be that we did not capture the important characteristics of the copulatory vibrational signals (e.g. signal amplitudes and/or intervals). Unfortunately, our method of recording vibrational signals did not provide reliable information on amplitude here, since it would be necessary to record from the copulating couple directly and not from the substrate. Investigation on amplitude of copulatory courtship signals, as well as further high-speed video recordings to reveal if only the male produces vibrations or if the female is also involved in signalling at this stage of mating, will therefore be a goal for subsequent experiments.

Fertility (measured as the percentage of hatched spiderlings vs. all eggs laid) was higher in females mated to males that had started to copulate sooner (Table 3). Hatching success was quite low overall (median $=20 \%$ for all good-condition males), so we cannot rule out that the laboratory conditions during development of the egg sacs might have affected the reproductive success. Since most of the poor-condition males were rejected by the female before copulation took place (three males were even attacked and killed), the sampling number for this group ( $n=10$ for successful insertion, $n=4$ with viable offspring) might be too small to reveal differences from the good-condition males.

Apart from gift quality and vibrational signals, chemical signals or cues might play an additional role in mate assessment. Chemical and vibrational signals are very often used in concert as multimodal signals (Uhl and Elias 2011). More research on 
Table 3 Generalized linear models with binomial distribution calculated for insertion (= mating) probability and fertility (number of hatched spiderlings vs. total number of eggs)

\begin{tabular}{lll}
\hline Insertion $\mathbf{y} / \mathbf{n}$ & $\chi^{2}$ & $\boldsymbol{p}$ \\
\hline Condition index & 3.61 & 0.057 \\
Latency & 0.18 & 0.672 \\
Number of pulses & 4.81 & 0.028 \\
Condition index*latency & 1.52 & 0.218 \\
Condition index*number of pulses & 0.00 & 0.997 \\
Latency*number of pulses & 0.70 & 0.402 \\
Condition index*latency*number of pulses & 7.25 & 0.007 \\
Fertility & $\chi^{2}$ & $\boldsymbol{p}$ \\
Condition index & 3.13 & 0.838 \\
Insertion latency & 337.18 & 0.045 \\
Insertion duration & 93.09 & 0.273 \\
Condition index*insertion latency & 54.24 & 0.400 \\
Condition index*insertion duration & 2.04 & 0.869 \\
Insertion latency*insertion duration & 139.77 & 0.183 \\
Condition index*insertion latency*insertion duration & 336.56 & 0.045
\end{tabular}

Significant $p$ values are highlighted in italics

multimodal signalling is needed to reveal the prevalence, information potential, the interplay and hierarchical levels between different types of information that influence mate choice.

Acknowledgements We thank Heidi Land for invaluable assistance during lab work and Timon Möller for the help with spider collection and maintenance. Brian Schulze is thanked for the assistance with high-speedvideo recordings. We are grateful to Cristina Tuni and to Monica Sheffer for the helpful comments; David Hosken and two anonymous reviewers provided detailed suggestions that improved the manuscript.

Authors' contributions MJBE designed the project, analysed the data and wrote the first draft of the manuscript. AM conducted the experiments and analysed the data. GU contributed to the project design and interpretation of the data. All the authors commented on previous versions of the manuscript. All the authors read and approved the final manuscript.

Funding Open Access funding enabled and organized by Projekt DEAL.

Data availability The datasets generated and analysed during the current study are included in this article and its supplementary information file.

\section{Compliance with ethical standards}

Conflicts of interest The authors declare that they have no conflict of interest.

Ethics approval Not applicable.

Open Access This article is licensed under a Creative Commons Attribution 4.0 International License, which permits use, sharing, adaptation, distribution and reproduction in any medium or format, as long as you give appropriate credit to the original author(s) and the source, provide a link to the Creative Commons licence, and indicate if changes were made. The images or other third party material in this article are included in the article's Creative Commons licence, unless indicated otherwise in a credit line to the material. If material is not included in the article's Creative Commons licence and your intended use is not permitted by statutory regulation or exceeds the permitted use, you will need to obtain permission directly from the copyright holder. To view a copy of this licence, visit http://creativecommons.org/licenses/by/4.0/.

\section{References}

Ahtiainen JJ, Alatalo RV, Kortet R, Rantala MJ (2004) Sexual advertisement and immune function in an arachnid species (Lycosidae). Behav Ecol 15:602-606. https://doi.org/10.1093/beheco/arh062

Albo MJ, Toft S, Bilde T (2011) Condition dependence of male nuptial gift construction in the spider Pisaura mirabilis (Pisauridae). J Ethol 29:473-479. https://doi.org/10.1007/s10164-011-0281-1

Albo MJ, Toft S, Bilde T (2012) Female spiders ignore conditiondependent information from nuptial gift wrapping when choosing mates. Anim Behav 84:907-912. https://doi.org/10.1016/j.anbehav. 2012.07.014

Albo MJ, Bilde T, Uhl G (2013a) Sperm storage mediated by cryptic female choice for nuptial gifts. Proc R Soc Lond B Biol Sci 280: 280. https://doi.org/10.1098/rspb.2013.1735

Albo MJ, Toft S, Bilde T (2013b) Sexual selection, ecology, and evolution of nuptial gifts in spiders. In: Macedo RH, Machado G (eds) Sexual Selection. Academic Press, San Diego, pp 183-200

Andersson M, Simmons LW (2006) Sexual selection and mate choice. Trends Ecol Evol 21:296-302. https://doi.org/10.1016/j.tree.2006. 03.015

Austad SN, Thornhill R (1986) Female reproductive variation in a nuptial feeding spider, Pisaura mirabilis. Bull Br Arachnol Soc 7:48-52

Barth FG (2002) A Spider's World - Senses and Behavior. SpringerVerlag, Berlin Heidelberg

Barth FG, Schmitt A (1991) Species recognition and species isolation in wandering spiders (Cupiennius spp.; Ctenidae). Behav Ecol Sociobiol 29:333-339. https://doi.org/10.1007/BF00165957

Becker E, Riechert S, Singer F (2005) Male induction of female quiescence/catalepsis during courtship in the spider, Agelenopsis aperta. Behaviour 142:57-70. https://doi.org/10.1163/ 1568539053627767

Bilde T, Tuni C, Elsayed R, Pekar S, Toft S (2007) Nuptial gifts of male spiders: sensory exploitation of the female's maternal care instinct or foraging motivation? Anim Behav 73:267-273. https://doi.org/10. 1016/j.anbehav.2006.05.014

Bradbury JW, Vehrencamp SL (2011) Principles of animal communication. Second Edition edn, Sinauer Associates, Sunderland, Massachusetts

Brown WD (1997) Courtship feeding in tree crickets increases insemination and female reproductive life span. Anim Behav 54:1369-1382. https://doi.org/10.1006/anbe.1997.0541

Byers J, Hebets E, Podos J (2010) Female mate choice based upon male motor performance. Anim Behav 79:771-778. https://doi.org/10. 1016/j.anbehav.2010.01.009

Cocroft RB, Rodríguez RL (2005) The behavioral ecology of insect vibrational communication. BioScience 55:323-334. https://doi.org/ 10.1641/0006-3568(2005)055[0323:TBEOIV]2.0.CO;2

Eberhard WG (1994) Evidence for widespread coursthip during copulation in 131 species of insects and spiders, and implications for 
cryptic female choice. Evolution 48:711-733. https://doi.org/10. 1111/j.1558-5646.1994.tb01356.x

Eberhard WG (1996) Female control: sexual selection by cryptic female choice. Princeton University Press, Princeton, New Jersey

Elias DO, Sivalinghem S, Mason AC, Andrade MCB, Kasumovic MM (2010) Vibratory communication in the jumping spider Phidippus clarus: substrate-borne courtship signals are important for male mating success. Ethology 116:990-998. https://doi.org/10.1111/j.14390310.2010.01815.x

Ghislandi PG, Beyer M, Velado P, Tuni C (2017) Silk wrapping of nuptial gifts aids cheating behaviour in male spiders. Behav Ecol 28:744-749. https://doi.org/10.1093/beheco/arx028

Gibson JS, Uetz GW (2008) Seismic communication and mate choice in wolf spiders: components of male seismic signals and mating success. Anim Behav 75:1253-1262. https://doi.org/10.1016/j. anbehav.2007.09.026

Greenfield MD (2002) Signalers and receivers: mechanisms and evolution of arthropod communication. Oxford University Press, Oxford

Hansen LS, Gonzalez SF, Toft S, Bilde T (2008) Thanatosis as an adaptive male mating strategy in the nuptial gift-giving spider Pisaura mirabilis. Behav Ecol 19:546-551. https://doi.org/10.1093/beheco/arm165

Hill PSM, Wessel A (2016) Biotremology. Curr Biol 26:R187-R191. https://doi.org/10.1016/j.cub.2016.01.054

Hoefler CD, Persons MH, Rypstra AL (2008) Evolutionarily costly courtship displays in a wolf spider: a test of viability indicator theory. Behav Ecol 19:974-979. https://doi.org/10.1093/beheco/arn055

Huber BA (1995) Copulatory mechanism in Holocnemus pluchei and Pholcus opilionoides, with notes on male cheliceral apophyses and stridulatory organs in Pholcidae (Araneae). Acta Zool 76:291-300. https://doi.org/10.1111/j.1463-6395.1995.tb01001.x

Jakob EM, Marshall SD, Uetz GW (1996) Estimating fitness: a comparison of body condition indices. Oikos 77:61-67. https://doi.org/10. $2307 / 3545585$

Kotiaho JS (2001) Costs of sexual traits: a mismatch between theoretical considerations and empirical evidence. Biol Rev 76:365-376. https://doi.org/10.1017/S1464793101005711

Kotiaho J, Alatalo RV, Mappes J, Parri S (1996) Sexual selection in a wolf spider: male drumming activity, body size, and viability. Evolution 50:1977-1981. https://doi.org/10.1111/j.1558-5646. 1996.tb03584.x

Land MF, Nilsson D-E (2012) Animal eyes, Second edn. Oxford University Press, Oxford, UK

Maklakov AA, Bilde T, Lubin Y (2003) Vibratory courtship in a webbuilding spider: signalling quality or stimulating the female? Anim Behav 66:623-630. https://doi.org/10.1006/anbe.2003.2245

Mappes J, Alatalo Rauno V, Kotiaho J, Parri S (1996) Viability costs of condition-dependent sexual male display in a drumming wolf spider. Proc R Soc Lond B Biol Sci 263:785-789. https://doi.org/10. 1098/rspb.1996.0117

Mortimer B (2017) Biotremology: do physical constraints limit the propagation of vibrational information? Anim Behav 130:165-174. https://doi.org/10.1016/j.anbehav.2017.06.015

Nitzsche ROM (1999) Das Brautgeschenk der Spinne. Rainar NITZSCHE Verlag, Kaiserslautern, Germany

Nitzsche ROM (2011) Courtship, mating and agonistic behaviour in Pisaura mirabilis (Clerck, 1757). Arachnology 15:93-120. https:// doi.org/10.13156/arac.2011.15.4.93

Parri S, Alatalo RV, Kotiaho J, Mappes J (1997) Female choice for male drumming in the wolf spider Hygrolycosa rubrofasciata. Anim Behav 53:305-312. https://doi.org/10.1006/anbe.1996.0371

Pekár S, Brabec M (2016) Modern analysis of biological data. Generalized linear models in R. Masaryk University Press, Brno

Peretti A, Eberhard WG, Briceño RD (2006) Copulatory dialogue: female spiders sing during copulation to influence male genitalic movements. Anim Behav 72:413-421. https://doi.org/10.1016/j. anbehav.2006.01.014
Prokop P (2006) Insemination does not affect female mate choice in a nuptial feeding spider. Ital J Zool 73:197-201. https://doi.org/10. 1080/11250000600727741

Prokop P, Maxwell MR (2012) Gift carrying in the spider Pisaura mirabilis: nuptial gift contents in nature and effects on male running speed and fighting success. Anim Behav 83:1395-1399. https://doi. org/10.1016/j.anbehav.2012.03.007

Prokop P, Semelbauer M (2017) Biometrical and behavioural associations with offering nuptial gifts by males in the spider Pisaura mirabilis. Anim Behav 129:189-196. https://doi.org/10.1016/j. anbehav.2017.05.027

Rivero A, Alatalo RV, Kotiaho JS, Mappes J, Parri S (2000) Acoustic signalling in a wolf spider: can signal characteristics predict male quality? Anim Behav 60:187-194. https://doi.org/10.1006/anbe. 2000.1452

Rodríguez RL (1998) Possible female choice during copulation in Ozophora baranowskii (Heteroptera: Lygaeidae): female behavior, multiple copulations, and sperm transfer. J Insect Behav 11:725741. https://doi.org/10.1023/a:1022303010790

Rodríguez RL (2019) Copulatory courtship with vibrational signals. In: Hill PSM, Lakes-Harlan R, Mazzoni V, Narins PM, Virant-Doberlet M, Wessel A (eds) Biotremology: studying vibrational behavior. Springer International Publishing, Cham, pp 79-89

Schäfer MA, Uhl G (2002) Determinants of paternity success in the spider Pholcus phalangioides (Pholcidae: Araneae): the role of male and female mating behaviour. Behav Ecol Sociobiol 51:368-377. https://doi.org/10.1007/s00265-001-0448-9

Stålhandske P (2001) Nuptial gift in the spider Pisaura mirabilis maintained by sexual selection. Behav Ecol 12:691-697. https://doi.org/ 10.1093/beheco/12.6.691

Suter RB, Renkes G (1984) The courtship of Frontinella pyramitela (Araneae, Linyphiidae): patterns, vibrations and functions. J Arachnol 12:37-54

Toft S, Albo MJ (2016) The shield effect: nuptial gifts protect males against pre-copulatory sexual cannibalism. Biol Lett 12:20151082. https://doi.org/10.1098/rsbl.2015.1082

Uhl G, Elias D (2011) Communication. In: Herberstein ME (ed) Spider behaviour: flexibility and versatility. Cambridge University Press, Cambridge, pp 127-189

Vahed K (1998) The function of nuptial feeding in insects: a review of empirical studies. Biol Rev 73:43-78. https://doi.org/10.1111/j. 1469-185X.1997.tb00025.x

Vahed K (2007) All that glisters is not gold: sensory bias, sexual conflict and nuptial feeding in insects and spiders. Ethology 113:105-127. https://doi.org/10.1111/j.1439-0310.2006.01312.x

Virant-Doberlet M, Cokl A (2004) Vibrational communication in insects. Neotrop Entomol 33:121-134. https://doi.org/10.1590/S1519$566 X 2004000200001$

Wignall AE, Herberstein ME (2013a) The influence of vibratory courtship on female mating behaviour in orb-web spiders (Argiope keyserlingi, Karsch 1878). PLoS One 8:e53057. https://doi.org/10. 1371/journal.pone.0053057

Wignall AE, Herberstein ME (2013b) Male courtship vibrations delay predatory behaviour in female spiders. Sci Rep 3:3557. https://doi. org/10.1038/srep03557

Wignall AE, Kemp DJ, Herberstein ME (2014) Extreme short-term repeatability of male courtship performance in a tropical orb-web spider. Behav Ecol 25:1083-1088. https://doi.org/10.1093/beheco/ aru083

Zahavi A (1975) Mate selection-A selection for a handicap. J Theor Biol 53:205-214. https://doi.org/10.1016/0022-5193(75)90111-3

Publisher's note Springer Nature remains neutral with regard to jurisdictional claims in published maps and institutional affiliations. 